\title{
Geographical variation of arsenic in rice from Bangladesh: Cancer risk
}

\author{
S. Islam ${ }^{1,2,3}$, M.M. Rahman ${ }^{1,2} \&$ R. Naidu ${ }^{1,2}$ \\ ${ }^{1}$ Global Centre for Environmental Remediation (GCER), Faculty of Science, \\ The University of Newcastle, Callaghan, NSW, Australia \\ ${ }^{2}$ Cooperative Research Centre for Contamination Assessment and Remediation of the Environment (CRC CARE), \\ The University of Newcastle, Callaghan, NSW, Australia \\ ${ }^{3}$ Department of Soil Science, Bangladesh Agricultural University, Mymensingh, Bangladesh
}

\begin{abstract}
This study analyzed 965 rice samples collected by household survey from Bangladesh to determine the distribution of arsenic (As), geographical variation, daily intake and the potential cancer risk form consuming rice. The results showed that As content in rice grain ranged between 3-680 $\mu \mathrm{g} / \mathrm{kg}^{-1}$ with the highest fraction being $98.6 \%$ of inorganic As. The daily intake of inorganic As from rice ranged between 0.38 to $1.92 \mu \mathrm{g} / \mathrm{kg}^{-1}$ body weight (BW). The incremental lifetime cancer risk (ILCR) for individuals due to the consumption of rice varied between $0.57 \times 10^{-3}$ and $2.88 \times 10^{-3}$ in different locations higher than the US EPA threshold.
\end{abstract}

\section{INTRODUCTION}

Arsenic is recognized as a toxic element and has been classified as a Group I human carcinogen. Arsenic exposure to humans mainly occurs via drinking As-contaminated water and consumption of food crops grown in irrigated agricultural lands where Ascontaminated groundwater is used for irrigation. In addition to supplying drinking water, As-contaminated groundwater is used extensively for the irrigation of crops in Bangladesh and West Bengal, India, especially for the cultivation of paddy rice during the dry season. As a result, food crops accumulate elevated levels of As so that it poses a potential threat to human health. Rice is the main dietary staple for many populations worldwide due to its nutritional value. Arsenic exposure from rice intake can be considerable and intake of inorganic As via this route is a significant risk factor for cancers, especially for the population who depend on rice diet substantively (Mondal \& Polya, 2008). In most developing countries, paddy rice is grown under flooded conditions and for this reason, the accumulation of As in rice grain is significant. Rice is more effective in As accumulation than other cereal crops such as wheat and barley (Williams et al., 2007). The objective of this study is to assess the distribution of As in rice from different locations of Bangladesh to understand the geographical variation and the potential cancer risk from consuming rice.

\section{METHODS}

For this study, we collected and analyzed 965 rice samples form 73 Upazilas (sub-districts) from 20 districts (Barisal, Chandpur, Comilla, Dhaka, Dinajpur, Faridpur, Gaibandha, Gopalganj, Lakshmipur, Lalmonirhat, Mymensingh, Naogaon, Narayanganj, Nawabganj, Netrokona, Noakhali, Rajshahi, Sherpur and Sylhet) of Bangladesh. Districts were selected based on the As concentrations (severely, moderately and less affected) in groundwater. The sampling sites are shown in Figure 1. The detail study results were reported elsewhere (Islam et al., 2017a, 2017b). Both dry (Boro) and wet (Aman) season's rice were included in this study. Most of the rice were local varieties, some high yielding variety and hybrid varieties were also included. Digestion of the rice samples for total As analysis was carried out employing the method used by Rahman et al. (2009). Inductively coupled plasma mass spectrometer (ICP-MS) (Agilent Technologies, Tokyo, Japan), was used to determine the amount of total As. For As speciation a liquid chromatography system (model 1100, Agilent Technologies, Tokyo, Japan) equipped with a guard and Hamilton PRP-X100 separation column, coupled with ICP-MS was used. Appropriate CRM was also used to verify the results of total As and As species in rice.

\section{RESULTS AND DISCUSSION}

Mean and median values of total As concentrations in rice grains are 126 and $107 \mu \mathrm{g} \mathrm{kg}^{-1}$, respectively, and the As level range between 3.4 and $680 \mu \mathrm{g} \mathrm{kg}^{-1}$, dry weight. These total As results are comparable to those previously found from Boro rice (range, $40-910 \mu \mathrm{g} \mathrm{kg}^{-1}$ ), and Aman rice (range, $<40-920 \mu \mathrm{g} \mathrm{kg}^{-1}$ ) samples in 25 districts throughout Bangladesh (Williams et al., 2006). Rice collected 
Table 1. Arsenic concentration and varietal differences in Bangladesh.

\begin{tabular}{ll}
\hline Rice genotypes & Concentration of As $\left(\mu \mathrm{g} \mathrm{kg}^{-1}\right)$ \\
\hline BRRI dhan33 & $137 \pm 11$ \\
Binadhan-7 & $166 \pm 07$ \\
BRRI dhan30 & $179 \pm 12$ \\
BR22 & $211 \pm 08$ \\
BR26 & $217 \pm 05$ \\
BR24 & $219 \pm 02$ \\
BRRI dhan47 & $104 \pm 09$ \\
BR14 & $152 \pm 05$ \\
BRRI dhan50 & $164 \pm 04$ \\
BRRI dhan29 & $166 \pm 01$ \\
BRRI dhan58 & $174 \pm 09$ \\
BRRI dhan28 & $174 \pm 08$ \\
Super hybrid & $210 \pm 11$ \\
Sonar Bangla hybrid & $285 \pm 16$
\end{tabular}

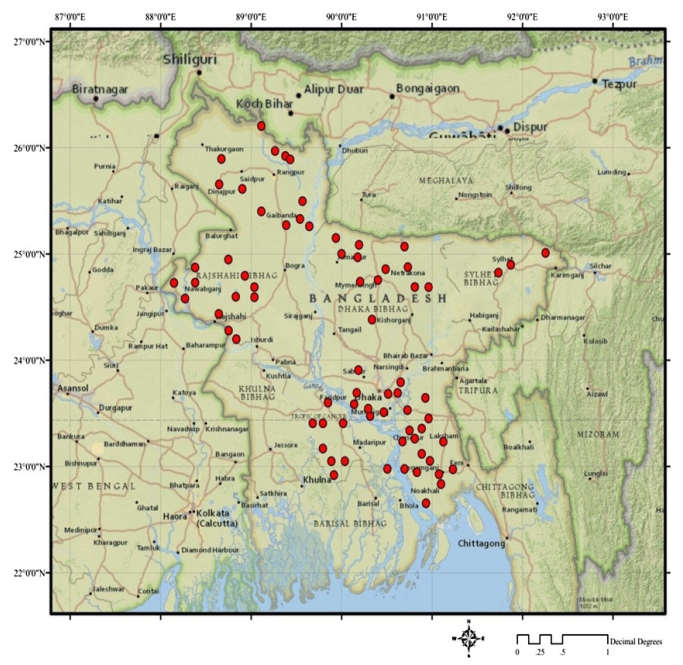

Figure 1. Sampling location in Bangladesh (red dots shows Upazilas) (Islam et al., 2017a).

from the markets showed that As concentrations ranged from $180-310 \mu \mathrm{g} \mathrm{kg}^{-1}$ in Aman rice and 210$270 \mu \mathrm{g} \mathrm{kg}^{-1}$ in Boro rice (Williams et al., 2006). Arsenic species results showed that inorganic As is predominant over organic As which ranges from 59 to $98 \%$ of the total As. Our results indicate that the aromatic rice varieties had less inorganic As compared to non-aromatic rice. The varietal differences on total As in rice grain in this study are summarized in Table 1.

About $47 \%$ of variation was accounted for by differences among the 73 upazilas, while $71 \%$ was due to differences between districts (Islam et al., 2017a). Much of the variation between samples could therefore be attributed to differences between districts (Fig. 2). The highest average daily intake of inorganic As from rice consumption in Narayanganj district was

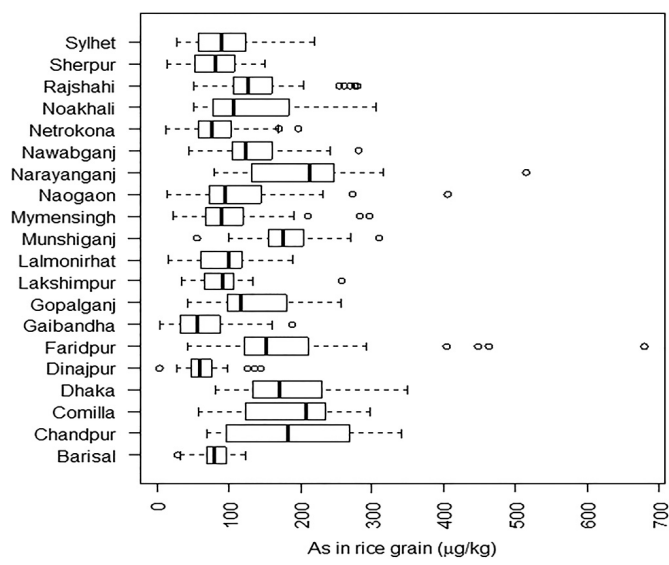

Figure 2. Statistical box plot of the concentrations of As in rice grain in 20 districts of Bangladesh (Islam et al., 2017a).

$1.92 \mu \mathrm{g} \mathrm{kg}^{-1} \mathrm{BW}$. The average incremental lifetime cancer risk (ILCR) value of inorganic As for consumers in Narayanganj district was $2.88 \times 10^{-3}, 288$ times higher than the acceptable limit (Islam et al., 2017a)

\section{CONCLUSIONS}

The study reveals that rice poses a significant risk to the local inhabitants. Further work is necessary to reduce the As levels from rice as well as to minimize the human exposure risk and potential cancer risk.

\section{REFERENCES}

Islam, S., Rahman, M.M., Islam, M.R. \& Naidu, R.. 2017a. Geographical variation and age-related dietary exposure to arsenic in rice from Bangladesh. Sci. Total Environ. 601: $122-131$.

Islam, S., Rahman, M.M., Islam, M.R. \& Naidu, R. 2017b. Inorganic arsenic in rice and cancer risk. Clean Up conference, Melbourne, Australia, 12-15 Sep.

Mondal, D. \& Polya, D.A. 2008. Rice is a major exposure route for arsenic in Chakdaha block, Nadia district, West Bengal, India: a probabilistic risk assessment. App. Geochem. 23(11): 2987-2998.

Rahman, M., Owens, G. \& Naidu, R.. 2009. Arsenic levels in rice grain and assessment of daily dietary intake of arsenic from rice in arsenic-contaminated regions of Bangladesh - implications to groundwater irrigation. Environ. Geochem. Health 31(1): 179-187.

Williams, P.N., Islam, M.R., Adomako, E.E., Raab, A, Hossain, S.A., Zhu, Y.G., Feldmann, J. \& Meharg, A.A. 2006. Increase in rice grain arsenic for regions of Bangladesh irrigating paddies with elevated arsenic in groundwaters. Environ. Sci. Technol. 40(16): 4903-4908.

Williams, P.N., Raab, A., Feldmann, J. \& Meharg, A.A., 2007. Market basket survey shows elevated levels of As in South Central U.S. Processed rice compared to California: consequences for human dietary exposure. Environ. Sci. Technol. 41(7): 2178-2183. 